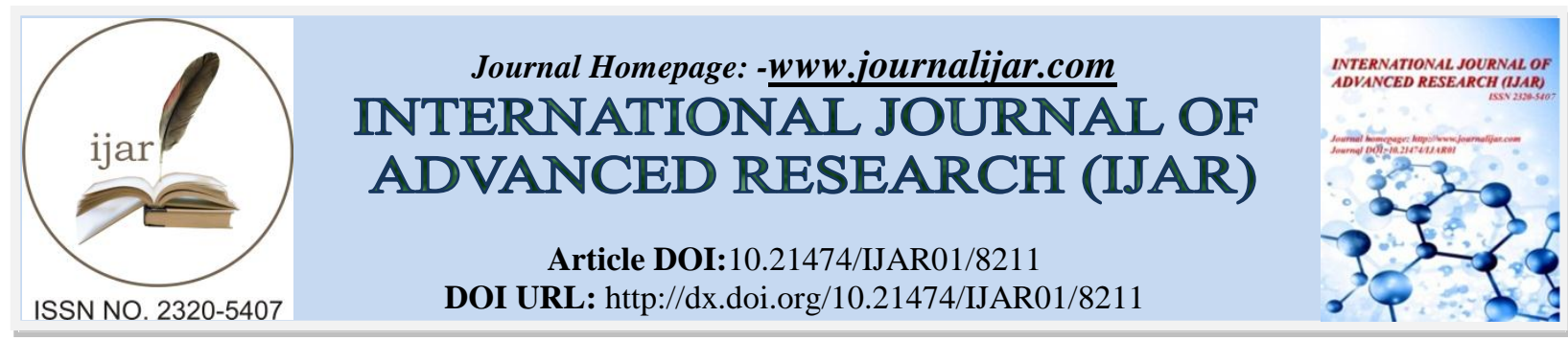

RESEARCH ARTICLE

\title{
PROGRESSIVE FAMILIAL HEART BLOCK ASSOCIATED WITH A MUTATION IN GENE TRPM4: A MOROCCAN FAMILY CASE.
}

\author{
Amine Qat ${ }^{1}$, Zakaria Raiss ${ }^{1}$, Ibtissam Fellat ${ }^{1}$, Mohamed Cherti ${ }^{1}$, and Ilham Ratbi ${ }^{2}$. \\ 1. Department of Cardiology B, University Hospital of Rabat, Morocco. \\ 2. Department of Medical Genetics, University Hospital of Rabat, Morocco.
}

\section{Manuscript Info}

Manuscript History

Received: 16 October 2018

Final Accepted: 18 November 2018

Published: December 2018

Keywords:-

TRPM4 ; Complete atrio-ventricular block; Progressive familial heart block

PFHB; Progressive cardiac conduction

defect PCCD; Permanent Pacemaker;

Genetic screening

\section{Abstract}

A 39 yo female patient was admitted for symptomatic complete atrioventricular Block. A family history and screening showed 5 cases of sudden death, and 4 cases of complete atrioventricular block, treated with Pacemaker implantation. Genetic screening showed a new variant in TRPM4 gene: c.512 G >A; p. Arg171Gln.

Copy Right, IJAR, 2018,. All rights reserved.

\section{Introduction:-}

Progressive familial heart block is an autosomal dominant cardiac conduction disorder that may progress to a complete atrioventricular block. A 39 yo female patient was admitted in June 2016 for symptomatic complete atrioventricular Block. A thorough family history and screening showed 5 cases of sudden death, and 4 others cases of members diagnosed with a symptomatic atrioventricular block that required a permanent implantation of Pacemaker. Genetic screening of the family, by targeted next-generation sequencing and Sanger technologies, showed a new variant in TRPM4 gene (Transient Receptor Potential Cation Channel Subfamily M Member 4): c.512 G >A; p. Arg171Gln, predicted pathogenous by genetic database.

\section{Case report:-}

The family case (Figure 1) started with the admission in June 2016 of Miss D. B, a 39 yo female patient for an episode of syncope.We found a complete A-V Block (Figure 2) with normal clinical and echocardiography findings. She was successfully implanted with regular follow-up.

\section{PM= Pacemaker}

Corresponding Author:-AmineQat.

Address:-Department of Cardiology B, University Hospital of Rabat, Morocco. 


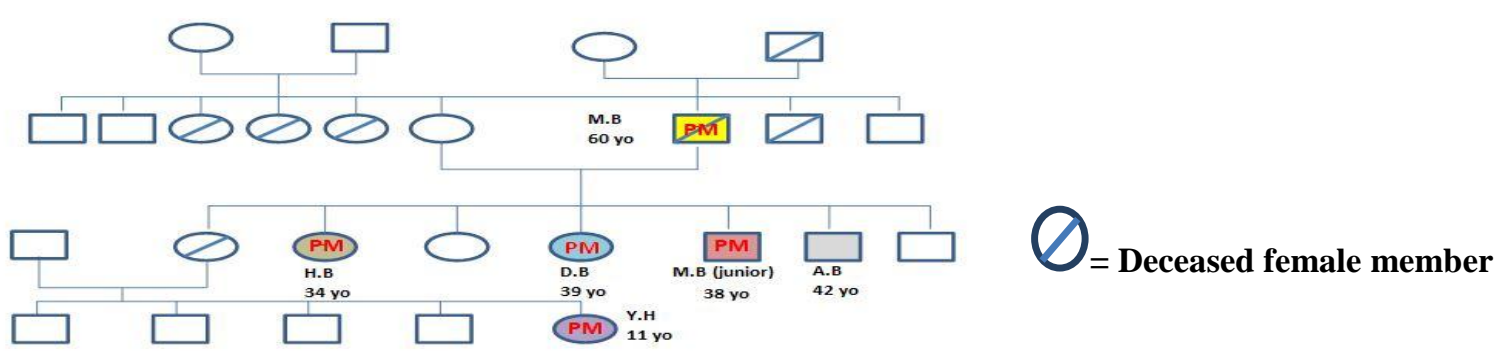

Figure 1:-Family tree.

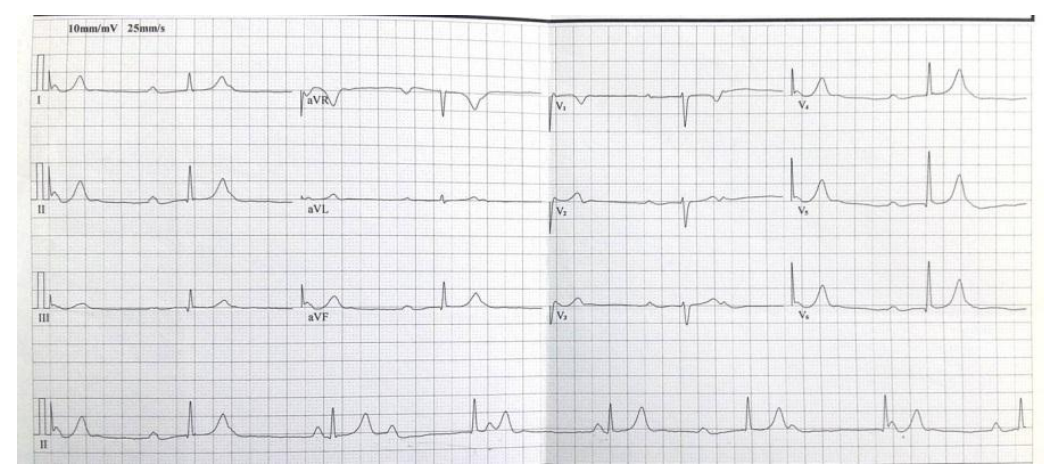

Figure 2:-ECG of D.B, showing a complete AV Block

Coincidentally, we found out in her family history that a younger sister, Miss H.B, 34 yo, was implanted 2 years ago abroad for the same etiology (symptomatic complete A-V Block with normal clinical exam and normal TTE). Therefore we decided to do a family screening, and we found out that the father, MrM. B, 60 yo, happened to have 4 deceased siblings ( 3 sisters before the age of 40, and 1 brother before the age of 50) of sudden death according to his testimony. His own medical exam revealed a symptomatic complete A-V Block (Figure 3) with Dilated LV and a depressed EF (Dilated cardiomyopathy DCM). He too was implanted, but sadly his DCMprogressively altered and he passed away2 years later.

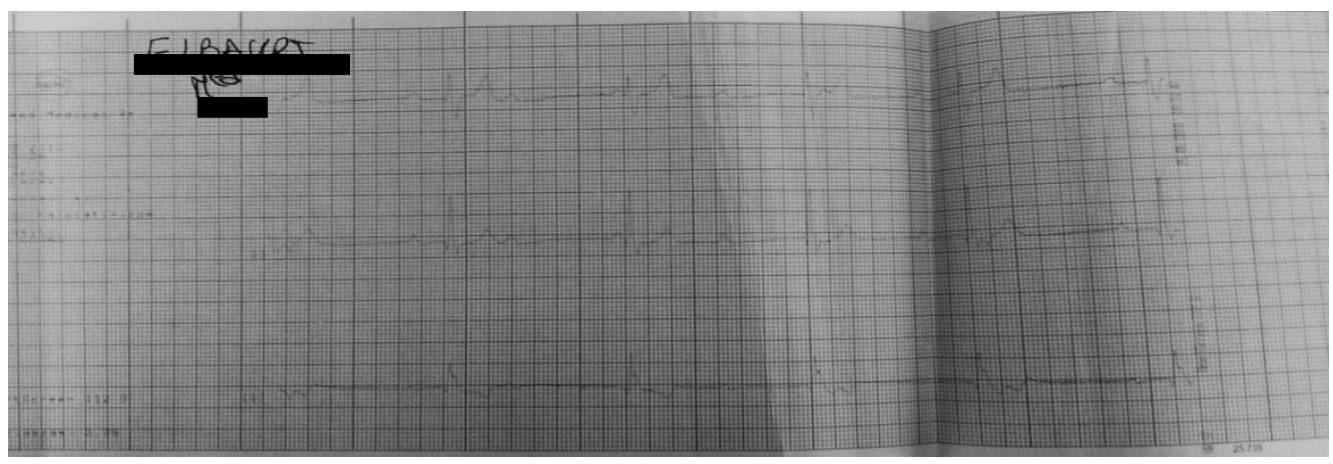

Figure 3:-ECG of the father M.B, showing a complete AV Block

For the othersiblings of Miss D.B, we found the brotherMr M.B (junior), 38 yo, who had a symptomatic complete A-V block with a Dilated LV and a preserved EF at the time of admission. He was successfully implanted, and a regular follow-up showed a deteriorating LVEF over the years (progression of DCM).

Another brother, Mr A.B, 42 yo, was complaining of atypical chest pain. Clinial exam, biology and TTE were normal. However, his ECG showed RBBB (Figure 4) and a 24h ECG Holter monitoring revealed a sinus node dysfunction (asymptomatic pauses) with sinus bradycardia (Figure 5). 


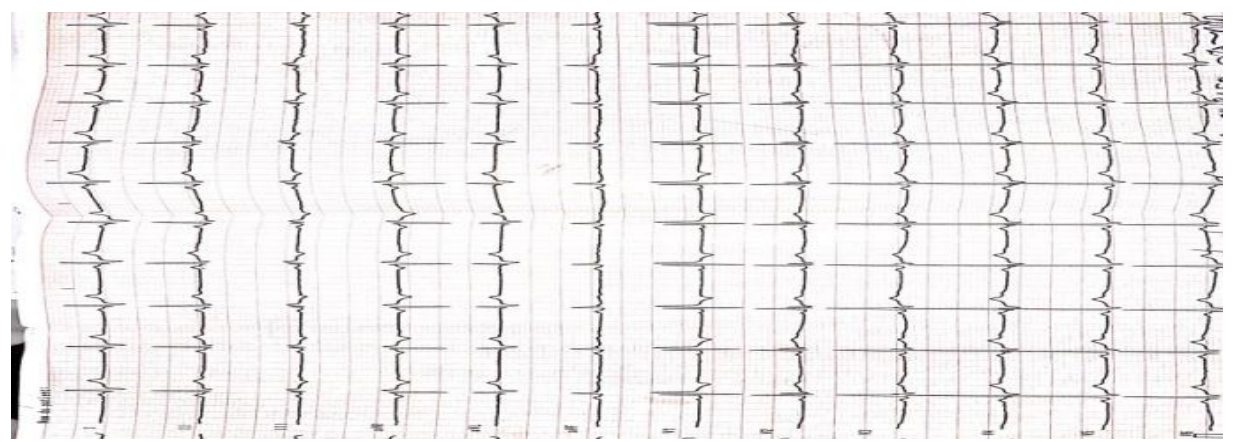

Figure 4:-ECG of the brother A.B showing Sinus rhythm + RBBB

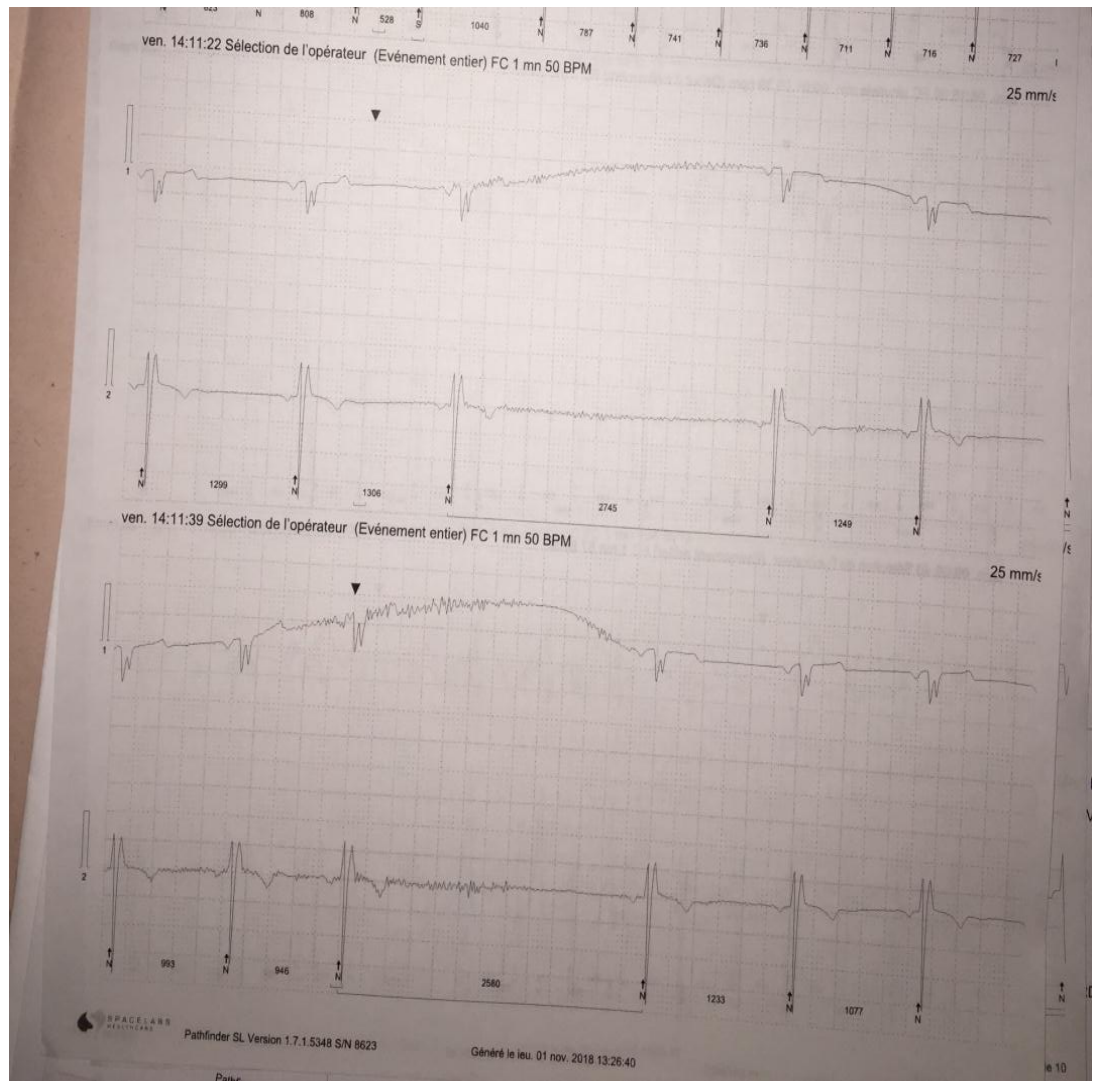

Figure 5:-ECG Holter of the brother A.B, showing a diurnal sinus pause of 2,7 sec.

Coincidentally, a deceased 34 yo sister 4 years ago (sudden death) had 5 children: 4 sons and 1 daughter. And in February 2018 we admitted the 11 yo niece Y. H, for a history of syncope. Medical exam showed a congenital heart disease with DCM (Figure 6) and a complete A-V Block (Figure 7). She was successfully implanted (Figure 8) with long-term epicardial pacemaker (Figure 9), with a good evolution and regular follow-up. 


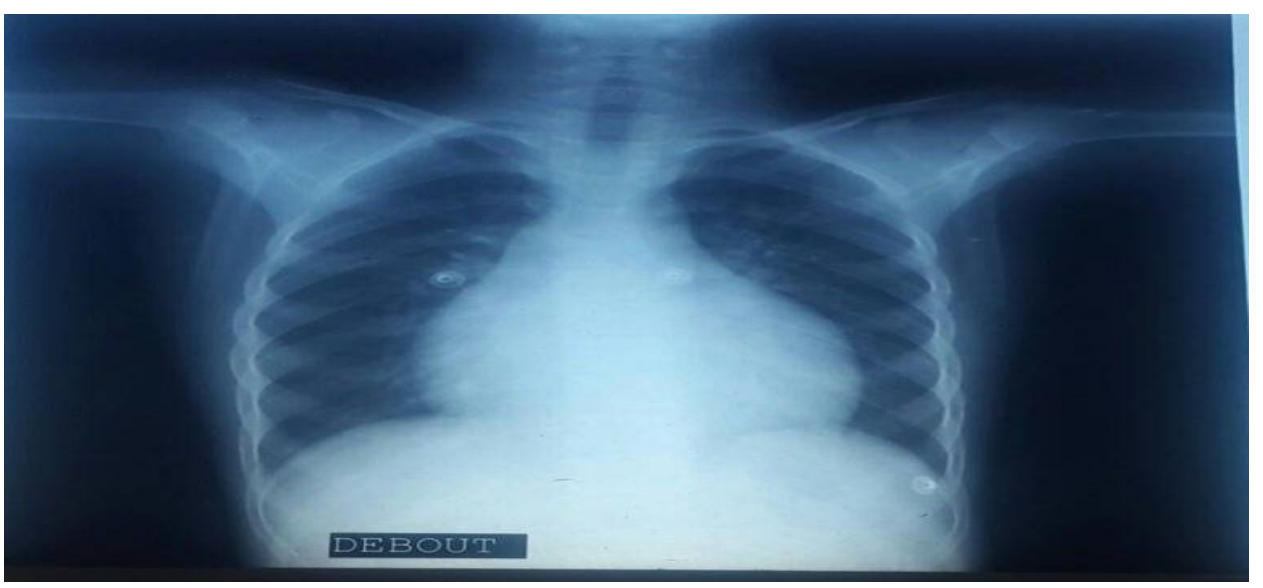

Figure 6:-Chest Radiography of the 11 yo niece Y.H, showing a large cardiomegaly.

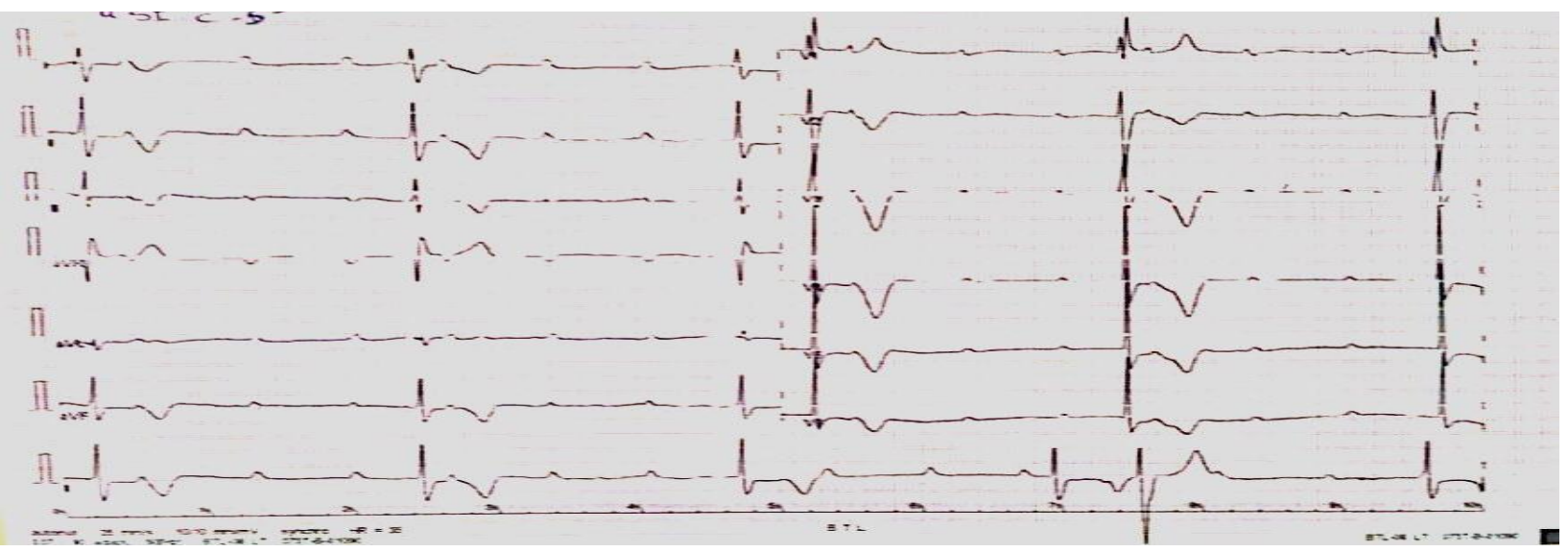

Figure 7:-ECG of Y.H, showing a complete AV Block
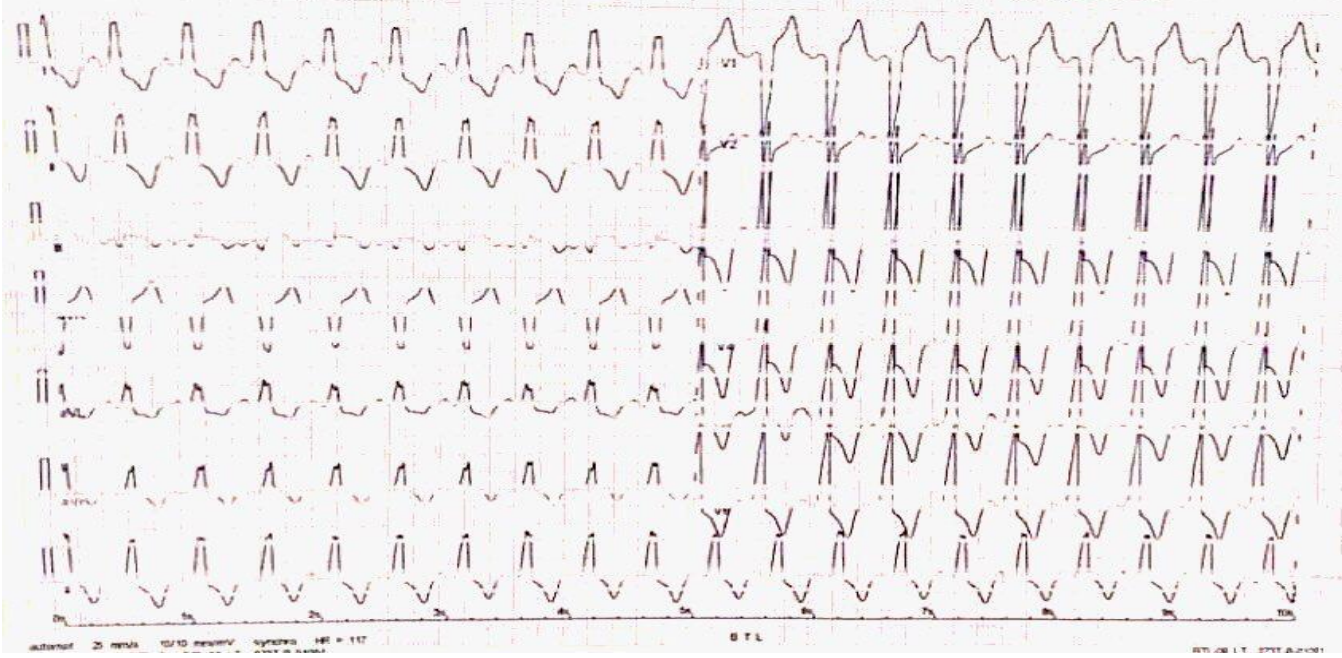

Figure 8:-ECG of Y.H, showing a paced rhythm 


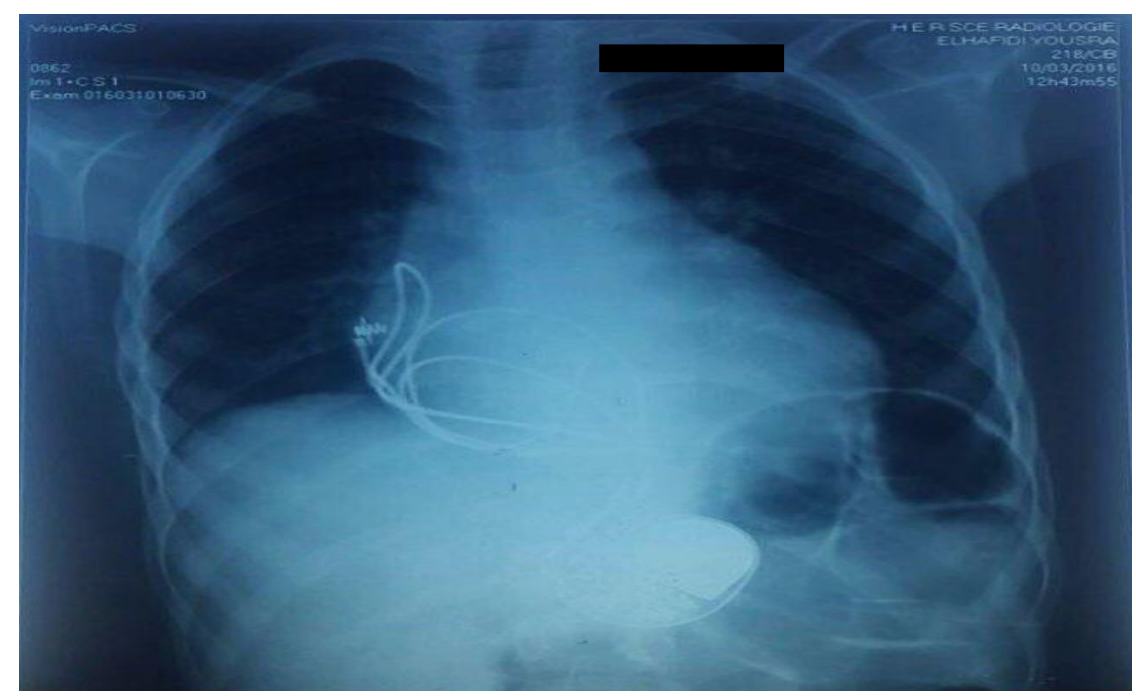

Figure 9:-Chest radiography of Y.H, after epicardial implantation

Screening of the nephews showed in 2 of the 4 boys, 13 yo Z.H (Figure 10) and 26 yo M.H (Figure 11), an abnormal ECG with bifascicular block (RBBB + LAFB). They were asymptomatic with normal TTE.

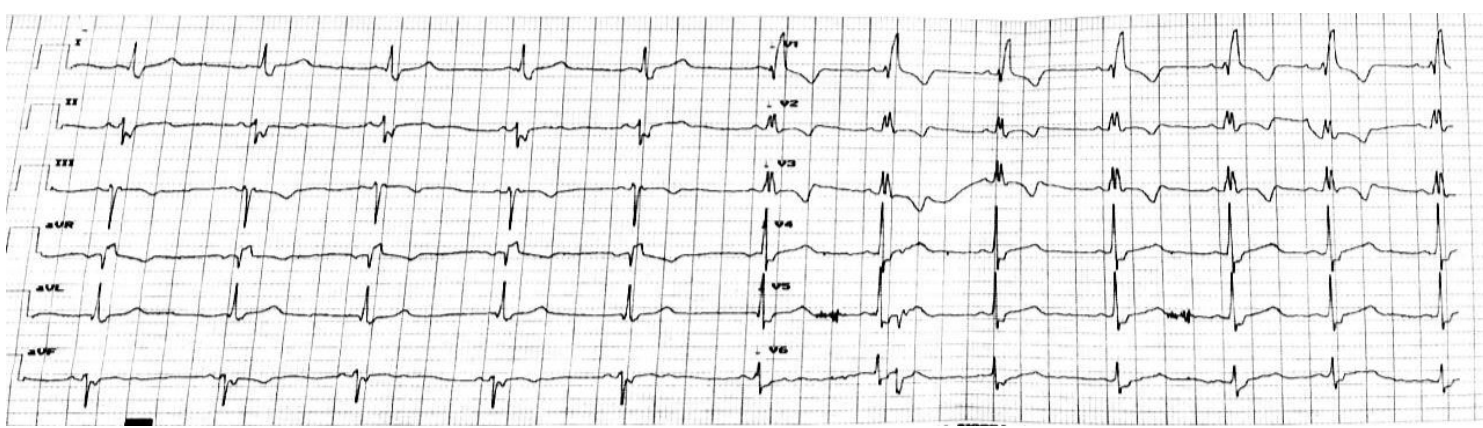

Figure 10:-ECG of 13 yo Z.H showing bifascicular block (RBBB + LAFB)

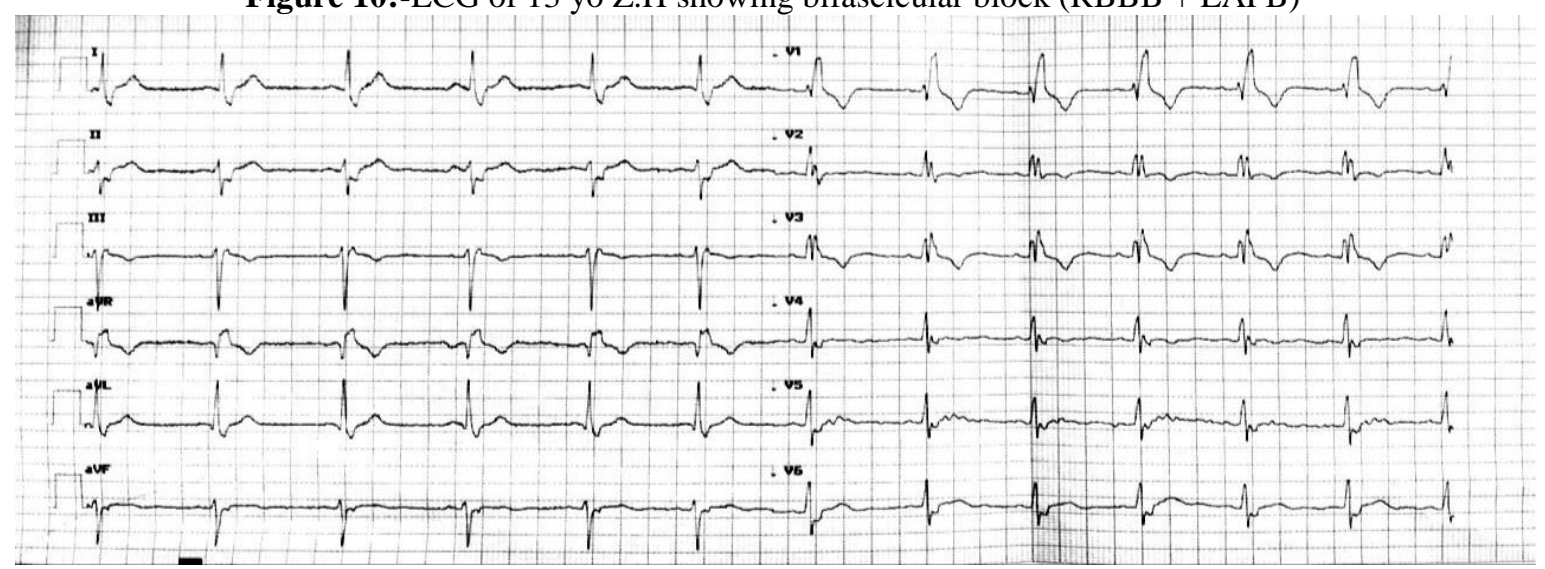

Figure 11:-ECG of 26 yo M.H showing bifascicular block (RBBB + LAFB)

Based on the recurrence of complete A-V block on the family through generations, we did a genetic testing and we found outthrough next generation sequencing (NGS) confirmed by Sanger sequencing technology, that the brothers M.B (junior), A.B and the sisters D.B and H.B carry aheterozygous mutation of TRPM4 gene:c.512 G $>$ A; p. Arg171GIn. On the other hand, another healthy brother and their mother don't carry the mutation.

The heterozygous missense mutation c.512 G >A; p. Arg171GIn isa new variant, and it is predicted to be pathogenous by genetic database. 


\section{Discussion:}

Progressive familial heart block (PFHB) was first described in the sixties by Lenègre [1] and Lev [2] as a fibrosis process affecting the conduction system. It is one of the most common cardiac conduction disturbances characterized by a progressive alteration of cardiac conduction through the His-Purkinje system with right or left bundle branch block (RBBB or LBBB) and widening of QRS complexes, leading to complete Atrio-Ventricular block, syncope and sudden death.

Familial cases of PFHB have been reported with an autosomal dominant inheritance and causally related to rare mutations in genes involved in cardiac impulse propagation (SCN5A [3,4], SCN1B [5] and TRPM4 [6,7]), in the structure of the nuclear lamina (LMNA [8,9]) and in cell-to-cell communication (GJA5 [10]).

Among these genes, TRPM4, encoding a calcium-activated cationic channel that is expressed in Purkinje fibers and nodal tissue [6,7], hasfirst been linked to progressive familial heart block type I (PFHBI) in two large pedigrees, respectively from South Africa (p.Glu7Lys) and Lebanon (p.Ala432Thr) [7].

PFHBI is associatedwith a progressive impairment of the His bundle branches conduction, typically startingwith RBBB and then left anterior hemiblock (LAHB) and thatmay progress to a complete AV block. QRS duration increases with time while PR and QTc intervals remain constant [11-12].

These ECG features differentiate type I PFHB from type II PFHB, in which the onset of complete heart block is associated with narrow QRS complexes [15]. Type I PFHB is manifested symptomatically when complete heart block develops, as dyspnea, syncopal episodes, or even sudden death.

In our case, all the family members that carried the mutation had a complete AV block, with the exception of one member (Mr A.B) who had RBBB and sinus dysfunction discovered on ECG Holter, with no aggravation of his conduction disturbances for a follow-up period of 8 years. Therefore, the possibility of the effect of the newly discovered TRPM4 variant (c.512 G >A; p. Arg171GIn) on not only atrioventricular but also sinoatrial conduction blocks was strongly discussed.

Type I PFHB was mapped to chromosome 19q13, and a novel causal gene, TRPM4, a member of the transient receptor potential melastatin family of ion channel genes, was identified by positional cloning [16].

Conduction defects in TRPM4-dependent familial cases were shown to be related to gain-of-function mutations proposed to be caused by a reduction of the deregulation of Small Ubiquitin MOdifierof TRPM4 channels and an impaired endocytosis resulting in stabilization and overexpression of mutant channels at the plasma membrane [6,7]. Since these two seminal reports, 18 gain- or loss-of-function variants have been identified as causing diverse forms of cardiac conduction defects and/or Brugadasyndrome [13-14].

Treatment of type I PFHB consists of the timely implantation of a permanent pacemaker. However, treatment with a prophylactic pacemaker is controversial [17]. Indeed, one of the family membersMr A.B, who carries the mutation, has 8 years of follow up with a constant ECG showing a RBBB and sinus dysfunction on ECG Holter. Thus, no pacemaker implantation was indicated in his case, for now. Follow-up of at least 6-months with ECG is recommended in patients with any degree of heart block, and at least once a yearin members of the affected families with a normal ECG [18].

Here in this case, using next generation sequencing (NGS) and Sanger technologies, we report anew TRPM4 variant(c.512 G >A; p. Arg171GIn)in a PFHBI Moroccan family.

TRPM4 gene is a causative gene in isolated cardiac conduction disease with mutations resulting in a gain of function and TRPM4 channel being highly expressed in cardiac Purkinje fibers, although in our case, one of the carriers of the mutation has a sinoatrial conduction block (sinus dysfunction), which strongly suggests its expression also on this site.

\section{Conclusion:}

The management of Progressive cardiac conduction disease (PCCD) is usually limited to an ECG monitoring as long as the conduction disturbancesare not too severe, otherwise apacemaker implantation will be indicated. 
In this case, we studied a Moroccan family that presented with PCCD through generations. Genetic sequencing of its symptomatic members found a new heterozygous missense mutation in TRPM4 gene (c.512 G >A; p. Arg171Gln).

Next generation sequencing offers good hopes at identifying new genetic factors responsible for conductive disturbances. Although genetic sequencing may not be a practical challenge, however results analysis remains very long and complex. Therefore, many genetic databases are developing such as Exome Variant Server or $1000 \mathrm{Genomes}$, in order to facilitate it. DNA is indeed still far from having revealed all its secrets.

\section{Conflict of interest:-}

The authors declare no conflict of interest.

\section{References:-}

1. J. Lenègre, Etiology and pathology of bilateral bundle branch block in relation to complete heart block, Prog. Cardiovasc. Dis. 6 (1964) 409-444, http://dx.doi.org/10.1016/S0033-0620(64)80001-3.

2. M. Lev, The pathology of complete atrioventricular block, Prog. Cardiovasc. Dis. 6

3. (1964) 317-326, http://dx.doi.org/10.1016/S0033-0620(64)80005-0.

4. J.-J. Schott, D.W. Benson, C.T. Basson, et al., Congenital heart disease caused by mutations in the transcription factor NKX2-5, Science 281 (1998) 108-111, http://dx.doi.org/10.1126/science.281.5373.108.

5. V. Probst, F. Kyndt, F. Potet, et al., Haploinsufficiency in combination with aging causes SCN5A-linked hereditary Lenègre disease, J. Am. Coll. Cardiol. 41 (2003)643-652, http://dx.doi.org/10.1016/S07351097(02)02864-4.

6. H. Watanabe, T.T. Koopmann, S. Le Scouarnec, et al., Sodium channel $\beta 1$ subunit mutations associated with Brugada syndrome and cardiac conduction disease inhumans, J. Clin. Invest. (2008)http://dx.doi.org/10.1172/JCI33891.

7. M. Kruse, E. Schulze-Bahr, V. Corfield, et al., Impaired endocytosis of the ion channel TRPM4 is associated with human progressive familial heart block type I, J. Clin. Invest. 119 (2009) 2737-2744, http://dx.doi.org/10.1172/JCI38292.

8. H. Liu, L.E. Zein,M. Kruse, et al., Gain-of-function mutations in TRPM4 cause autosomal dominant isolated cardiac conduction disease, Circ. Cardiovasc. Genet. 3 (2010) 374-385, http://dx.doi.org/10.1161/CIRCGENETICS.109.930867.

9. D. Fatkin,C.MacRae, T. Sasaki,etal.,Missensemutationsintheroddomainof the laminA/C gene as causes of dilated cardiomyopathy and conduction-system disease, N. Engl.

10. J. Med. 341 (1999) 1715-1724, http://dx.doi.org/10.1056/NEJM199912023412302.

11. C.-C. Lai, Y.-H. Yeh, W.-P. Hsieh, et al.,Whole-exome sequencing to identify a novel

12. LMNA gene mutation associated with inherited cardiac conduction disease, PLoSOne 8 (2013)http://dx.doi.org/10.1371/journal.pone.0083322.

13. N. Makita, A. Seki, N. Sumitomo, et al., A Connexin40 mutation associatedwith a malignant variant of progressive familial heart block type I, Circ. Arrhythm. Electrophysiol. 5 (2012) 163-172, http://dx.doi.org/10.1161/CIRCEP.111.967604.

14. J.M. Combrink,W.H. Davis, H.W. Snyman, Familial bundle branch block, Am. Heart J.64 (1962) 397-400, http://dx.doi.org/10.1016/0002-8703(62)90156-4.

15. E. Stéphan, Hereditary bundle branch system defect: survey of a family with four affected generations, Am. Heart J. 95 (1978) 89-95, http://dx.doi.org/10.1016/0002-

16. $8703(78) 90401-5$.

17. M. Kruse, O. Pongs, TRPM4 channels in the cardiovascular system, Curr. Opin. Pharmacol. 15 (2014) 68-73, http://dx.doi.org/10.1016/j.coph.2013.12.003.

18. B. Stallmeyer, S. Zumhagen, I. Denjoy, et al., Mutational spectrum in the Ca2+- activated cation channel gene TRPM4 in patients with cardiac conductance disturbances, Hum. Mutat. 33 (2012) 109-117, http://dx.doi.org/10.1002/humu.21599. 